oesophageal or duodenal stenosis, especially if the child has Down's syndrome or some congenital anomaly of the alimentary tract. A small tracheo-oesophageal fistula may pass undiagnosed for several months; when a stomach tube is passed, with the proximal end under water, and the tube is slowly withdrawn up the oesophagus, bubbles may reveal the presence of the fistula. Sometimes coeliac disease presents as vomiting. Other remote possibilities are allergy to cows' milk or increased intracranial pressure. Finally a child may be brought to the doctor with vomiting when the history indicates that he vomits only when he has a spasm of coughing, and the cause is whooping cough.

The good clinician makes his diagnosis by a careful, detailed history, by observation and examination of the child, and then by sitting down and thinking-before deciding whether any investigations are needed. His decisions are based on clinical judgment, and he should be prepared to make a mistake.

1 Illingworth, R S, and Lister, J, fournal of Pediatrics, 1964, 65, 839.

2 Brockbank, E M, British Medical fournal, 1907, 1, 421.

${ }^{3}$ Cameron, H C, British Medical fournal, 1925, 1, 872.

- Richmond, J B, and Eddy, E J, American Fournal of Diseases of Children, $1957,94,412$.

5 Richmond, J B, Eddy, E J, and Green, M, Pediatrics, 1958, 22, 49.

6 Fullerton, D T, Archives of General Psychiatry, 1963, 9, 593.

${ }^{7}$ Menking, M, et al, New England fournal of Medicine, 1969, 280, 802.

8 Stein, M L, Rausen, A R, and Blau, A, Fournal of the American Medical Association, 1959, 171, 2309.

${ }^{9}$ Fleisher, D R, American fournal of Diseases of Children, 1979, 133, 266.

10 Luckey, R E, Watson, C M, and Musick, J K, American fournal of Mental Deficiency, 1968, 73, 139.

11 1959-1960 Year Book of Pediatrics, p 421. Chicago, Year Book Medical Publishers Inc, 1961.

12 Herbst, J, Friedland, G W, and Zboralske, F F, Fournal of Pediatrics, 1971, 78, 261 .

${ }^{13}$ Hillman, R E, Keating, J P, and Williams, J C, fournal of Pediatrics, 1978, 92, 439.

14 Christie, D L, O'Grady, L R, and Mack, D V, Fournal of Pediatrics, 1978, 93, 23.

15 Abrahams, P, and Burkitt, B F E, Australian Paediatric fournal, 1970, 6, 41 .

${ }^{16}$ Sondheimer, J M, and Morris, B A, Fournal of Pediatrics, 1979, 94, 710.

17 Kinsbourne, M, Lancet, 1964, 1, 1058.

\section{Cubital tunnel syndrome}

In contrast to the many articles published on the carpal tunnel syndrome, little information is available about the cubital tunnel syndrome-ulnar nerve compression at the elbow. Panas $^{1}$ elegantly described four cases in 1878; one patient had his elbow explored and subsequently died of wound infection. After this surgical interest lagged, apart from occasional case reports, until Feindal and Stratford ${ }^{2}$ described compression of the nerve by a fibrous aponeurosis stretching between the humeral and ulnar heads of flexor carpi ulnaris. Like Osborne ${ }^{3}$ and Clark $^{4}$ they favoured simple decompression rather than the more elaborate process of transposing the nerve. Diagnosis of earlier, milder cases more amenable to treatment became possible with the advent of electrodiagnosis. ${ }^{5}$

The factors that may play a part in causing the condition include decubitus pressure during anaesthesia, occupational pressures, sleep, bed rest, and unpadded elbow crutches. Chronic deformity of the elbow joint may cause recurrent dislocation of the nerve from the sulcus, or the nerve may be damaged by acute trauma. Ulnar nerves impaired by diabetes, alcoholism, leprosy, or hereditary neuropathy are more susceptible to entrapment pressure. Ischaemic mononeuropathy may occur at the elbow as a result of subacute vasculitis of the vasa nervorum in rheumatoid arthritis and polyarteritis nodosa. Yet despite this wide range of predisposing causes none can be identified in about one-third of cases.

Most patients present with both motor and sensory symptoms. When the fibres compressed are mainly motor appreciable weakness may develop before the patient seeks help-whereas the predominantly sensory symptoms in median nerve compression usually prompt earlier referral. Typically, there is slight clawing of the fourth and fifth fingers, impaired sensation over the fifth finger and the ulnar side of the fourth, and weakness and wasting of hypothenar and interosseous muscles. Because of weakness of adductor pollicis adduction of the thumb can be achieved only through flexor pollicis longus, causing flexion of the thumb tip (Froment's sign). There may be weakness of ulnar deviation of the wrist (flexor carpi ulnaris) and flexion of the tips of the fourth and fifth fingers (flexor digitorum profundus), which confirms that the lesion is at or above the elbow.

Payan $^{6} 7$ has studied the electrodiagnosis of ulnar nerve compression and its response to transposition. The segment of the nerve that traverses the cubital tunnel is subjected to standard tests of motor and sensory conduction and compared with other segments of the same nerve and of the other ulnar nerve. The most common finding is slowing of motor and sensory conduction across the sulcus. Prolonged latency and increased temporal dispersion of the response evoked in flexor carpi ulnaris is a useful sign in severe cases, where fibres to the hand may have ceased to conduct. The sensory volleys recorded from the fifth finger will be appreciably reduced compared with those from the second finger. Differential diagnosis needs to distinguish intravertebral compression of the eighth cervical nerve, which produces weakness and denervation of the thumb extensor and abductor muscles. Since the root lesion is proximal to the sensory ganglion the ulnar sensory action potentials are normal. Compression of the first thoracic root in the thoracic outlet usually produces signs of denervation of the thenar muscles and the motor conduction studies usually give normal results.

Several points about management are worth emphasising. When the nerve damage is due to closed trauma there may be a predominant neurapraxia from local demyelination of the conducting fibres; spontaneous recovery may be expected in several months. More severe damage causes degeneration (axonotmesis) of fibres, attenuation of conduction, and signs of denervation in the muscles supplied. Since reinnervation proceeds at an average rate of $1 \mathrm{~mm}$ a day it will take at least a year to reach the hand. Serial electrodiagnostic studies will help to show whether recovery is occurring and, if not, whether the nerve needs decompression. Finally, all concerned need to remember that no recovery can be expected in the hand until over a year after transposition for chronic compression.

I Panas, P, Archives Générales de Médecine, 1878, 2, 5

2 Feindal, W, and Stratford, J, Canadian fournal of Surgery, 1958, 1, 287.

3 Osborne, G V, Postgraduate Medical fournal, 1959, 35, 392.

4 Clark, C B, Fournal of the American Medical Association, 1979, 241, 801.

Simpson, J A, Journal of Neurology, Neurosurgery, and Psychiatry, 1956 $19,275$.

6 Payan, J, fournal of Neurology, Neurosurgery, and Psychiatry, 1969, 32, 208

' Payan, J, Fournal of Neurology, Neurosurgery, and Psychiatry, 1970, 33, 137. 